\title{
ANÁLISE DOS ASPECTOS AMBIENTAIS DO DESIGN DE EMBALAGENS DE AÇUCAR MASCAVO ORGÂNICO
}

\author{
Elisa Jorge Quartim Barbosa, (FAU USP); Denise Dantas, Dra. (FAU USP)
}

PALAVRAS CHAVE
Embalagem, orgânicos, ambiental, percepção

KEY WORDS

Packaging, organic, environmental, perception.

\section{RESUMO}

Esta pesquisa buscou perceber se os princípios agroecológicos utilizados na produção dos produtos orgânicos industrializados se refletem nas embalagens de açúcar mascavo e se estes são percebidos pelos consumidores. Foi feito um estudo comparativo entre duas indústrias de alimentos orgânicos, definidas após uma pesquisa de campo, e entrevistas em profundidade com os responsáveis pelo desenvolvimento de embalagens e com os consumidores. Os dados da pesquisa mostraram que não há alinhamento entre o discurso e a prática no que diz respeito ao design das embalagens. Os consumidores têm dificuldade em perceber os diferenciais do produto orgânico apenas pela embalagem, o que sugere que os quesitos não verbais representados pelos elementos simbólicos e metafóricos no seu design deveriam ser mais valorizados. Assim como também a localização das informações e o material da embalagem.

\footnotetext{
ABSTRACT

This research attempted to understand if the agroecological principles, used in the production of organic products, are reflected in the brown sugar packaging and if these are perceived by consumers. A comparative study was made between two industries of organic foods, defined after field research and interviews with packaging developers and consumers. The survey data showed that there is no alignment between theory and practice in packaging design. Consumers have difficulty realizing the organic product differentials only by the packaging, which suggests that the non-verbal questions posed by symbolic and metaphorical elements in design should be more valued. As well as the location of information and the packaging material.
} 


\section{INTRODUÇÃO}

A embalagem é parte integrante da crescente demanda por alimentos orgânicos que vem exercendo grandes mudanças nas indústrias. Os produtos orgânicos possuem, em seu próprio conceito, a preocupação da redução do impacto da sua produção no meio ambiente, porém nem sempre isso se reflete no design de suas embalagens.

Este estudo tem o objetivo de verificar se há coerência entre o design das embalagens de açúcar mascavo orgânico, presentes no mercado paulistano entre 2011 e 2013, e seu conteúdo, no que diz respeito aos critérios ambientais, entender a percepção dos consumidores em relação a essas embalagens, buscando identificar se há ou não deficiência de projeto nesse segmento que possa comprometer a compreensão do usuário em relação aos benefícios dessa categoria de produtos.

Para isso o método escolhido foi um estudo comparativo entre duas indústrias de alimentos orgânicos, definidas após uma pesquisa de campo. E entrevistas em profundidade com os responsáveis pelo desenvolvimento de embalagens nas indústrias e no escritório de design e com os consumidores.

exemplo, na Itália onde o lixo previamente selecionado pode ser depositado em lixeiras diferenciadas (por forma e cor) nas lixeiras nas ruas. $O$ cidadão também recebe recipientes menores para ter em casa os quais serão esvaziados pela empresa de coleta do lixo em dias pré-estabelecidos (ver Figura 2).

A coleta seletiva permite também de selecionar resíduos não recicláveis ou reutilizáveis que mesmo assim podem ainda ter uma função útil na produção de energia (térmica, por exemplo) em vez de ocupar espaço em aterros ou em outros lugares não aptos para o armazenamento (o mar, por exemplo).

Os focos do estudo foram dois: investigar um sistema exemplar de coleta seletiva e tratamento de resíduos que resulta em alto percentual de coleta seletiva e geração de energia por biogás - o caso de Tortona; e investigar coleta seletiva com resultado potencializado: a geração de calor e energia através da incineração de resíduos não recicláveis: o caso do TU da Brescia. O trabalho aqui apresentado tem como propósito relatar estas duas experiências exemplares de coleta seletiva e geração de energia, apresentando a estrutura, organização, procedimentos e resultados destas atividades.

\section{DESENVOLVIMENTO}

A embalagem, por ser um produto de rápido consu- mo e consequente descarte, pode causar grandes impactos ambientais caso não seja bem projetada, como a geração de resíduos e o grande consumo de matérias-primas não renováveis.

O pressuposto da pesquisa é que as embalagens de açúcar mascavo orgânico podem não refletir, para o consumidor, a preocupação de redução do impacto ambiental de sua produção, dificultando a identificação do seu diferencial em relação à outras marcas não orgânicas.

O objeto de estudo desta pesquisa são as embalagens de açúcar mascavo orgânico, produzidos e comercializados em lojas de produtos naturais e em supermercados na cidade de São Paulo, após a aprovação do selo de certificação de orgânicos pelo Ministério da Agricultura, Pecuária e Abastecimento (MAPA) em 2011, com ênfase nos requisitos ambientais de design aplicados no seu desenvolvimento. As empresas que atenderam aos requisitos acima explicitados foram: Mãe Terra e Via Pax Bio.

Esta pesquisa utilizou métodos de abordagem qualitativa, devido à subjetividade dos dados que não podem ser traduzidos em números, e sim interpretados, atribuindo-se a eles significados.

Para a obtenção dos dados, foi feito um estudo comparativo para descobrir padrões e perceber semelhanças e diferenças dos casos estudados, explicitando as especificidades do design das embalagens de arroz orgânico e suas percepções.

Para conhecer melhor a política de desenvolvimento de embalagens, primeiramente foi feito um mapeamento de 2011 até 2013 do que é declarado pela empresa em seus materiais de divulgação, como sites e redes sociais.

A fim de obter detalhes e peculiaridades, foram feitas entrevistas profundidade, semiestruturadas, com pessoas que participaram do desenvolvimento das embalagens, produtores e designers, e com consumidores de alimentos industrializados, visando a proporcionar uma visão geral das políticas de desenvolvimento de embalagens e a percepção dos consumidores quanto às características inerentes aos alimentos orgânicos.

Foram selecionados consumidores de alimentos, de 25 a 75 anos, que vivem da região da Grande São Paulo, que costumam fazer compras para a sua casa e que não tivessem um conhecimento prévio sobre o que era a pesquisa. Foram realizadas 32 entrevistas no período de julho a setembro de 2013 , onde foram apresentadas embalagens de alimentos orgânicos de farinha de trigo, açúcar mascavo, arroz, feijão, cookie, barra de cereais, granola e macarrão instantâneo. Para este artigo serão 
apresenta-dos os resultados relacionados às embalagens de açúcar mascavo orgânico que foram mostradas para sete consumidores.

Os dados de uma entrevista não são suficientes para perceber se o entrevistado identifica ou não um alimento orgânico pela embalagem, pois as perguntas, mesmo abertas, poderiam influenciar as respostas. Por esse motivo, durante a entrevista foi feito um experimento, onde foi apresentado um grupo de embalagens de açúcar mascavo, sobre uma mesa, podendo assim determinar quais eram as variáveis que influenciam na escolha de um produto, e se a sua produção com um menor impacto ambiental era um deles.

Foi pedido para que ele separasse as embalagens em dois grupos, em orgânicos e não orgânicos. O objetivo era perceber o que ele olha na embalagem para separar e se buscava o selo de certificação de produto orgânico.

Apenas após o experimento é que foram feitas questões específicas sobre os alimentos orgânicos para um melhor detalhamento da percepção do nível de conhecimento sobre esse tipo de produto e se relaciona com um produto de baixo impacto ambiental.

As entrevistas e os estudos comparativos foram importantes para verificar se há coerência entre o design das embalagens e seu conteúdo, no que diz respeito à especificidades dos alimentos orgânicos, indicando a presença ou não de uma deficiência nesse segmento nos casos estudados.

\subsection{Análise dos dados}

A análise dos dados das entrevistas utilizou o método de análise do discurso e análise do conteúdo. Para a análise do conteúdo, foram definidas categorias de unidades de texto e expressões que emergiram das respostas das entrevistas e baseadas na teoria pesquisada. Para análise do discurso, foram identificados padrões e funções no discurso baseados nos dados que emergiram da análise de conteúdo.

A análise das embalagens de açúcar mascavo orgânico pretendeu verificar se os atributos de design presentes nas embalagens são capazes de comunicar as especificidades dos orgânicos incluindo a forma de sua produção. Elas foram feitas com base nas informações não verbais representadas nas embalagens, e por seus elementos simbólicos e metafóricos, codificados em signos e sintaxes específicas. Foram considerados também os padrões primários de varredura do campo e a localização das informações, como o centro de atenções, a área de maior tensão visual e hierarquia de leitura.

A análise da estrutura perceptiva e funcional da embalagem ajudou a extrair dados que possibilitaram a interpretação da comunicação e pregnância das formas. Os valores, analogias e associações foram confrontados com o que foi transmitido pelos consumidores nas entrevistas.

\subsection{Referencial Teórico}

Para estruturar metodologicamente a pesquisa, foram utilizados os livros de Uwe Flick (2009), Augusto Triviños (1987), Maria Rosa e Marlene Arnoldi (2006) e Martin Bauer e George Gaskel (2002).

Quando abordado o tema de produção de produtos e embalagens com menor impacto ambiental, foi usado o livro Cradle to cradle (MCDONOUGH; BRAUNGART, 2002) que descreve ser possível integrar os sistemas industriais com os naturais. E Haverá a idade das coisas leves (KAZAZIAN, 2005), por fazer uma reflexão sobre os objetos do nosso cotidiano que poderiam se tornar mais leves e duráveis.

Sobre o design de embalagem, foi usado o livro Packaging sustainability (JEDLIČKA, 2009) que dá uma ampla visão de soluções para desenvolver embalagens mais sustentáveis e integradas aos sistemas de produção.

A análise da estrutura visual das embalagens foi fundamentada Gestalt nos livros de Donald Hoffman (2001), Donis A. Dondis (1997) e na semiótica com os livros de Lucrécia Ferrara (1993) e Lucia Santaella (2005).

A estratégia de análise final dos dados, combinando os diversos métodos, foi a de triangulação dos dados colhidos nas entrevistas e na análise das embalagens.

\subsection{Alimentos orgânicos}

Para um alimento ser considerado orgânico, deve ser produzido em um ambiente onde se utilizam como base do processo produtivo os princípios agroecológicos que contemplam o uso responsável do solo, da água, do ar e dos demais recursos naturais, respeitando as relações sociais e culturais. (EMBRAPA, 2008)

Desde janeiro de 2011, é obrigatório apresentar o selo do Sistema Brasileiro de Avaliação da Conformidade Orgânica (SisOrg) na embalagem para que o produto possa ser comercializado em lojas e mercados (MAPA, 2012).

Com o aumento do uso indiscriminado de agrotóxicos e fertilizantes químicos na agricultura convencional, consumidores de alimentos cada vez mais buscam alternativas para poder se alimentar de forma mais saudável e cuja produção esteja mais integrada com a natureza, en- 
contrando nos alimentos orgânicos essa opção.

O que se destaca no alimento orgânico em relação ao convencional é a ausência de resíduos de agrotóxicos mantendo o solo sadio, observando cuidadosamente os níveis controláveis de pragas para aumentar suas colheitas.

Figura 1- Selo do Sistema Brasileiro de Avaliação da Conformidade Orgânica.

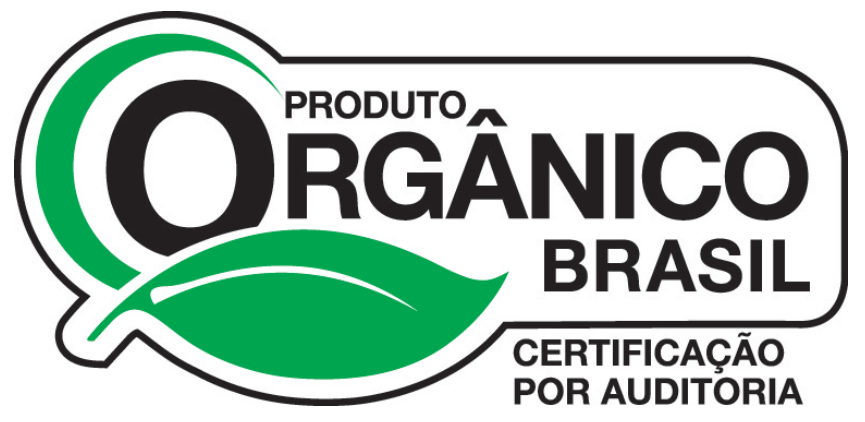

Fonte: MAPA, 2011

A agricultura orgânica busca diversificar e integrar a produção de espécies vegetais e animais com o objetivo de criar ecossistemas mais equilibrados (MAPA, 2012), sem depender de produtos químicos externos. A embalagem deve expressar visualmente todas as características de uma produção ecológica, para que o consumidor o adquira.

\subsection{Design de embalagens de açúcar mascavo orgânico}

A embalagem se apresenta como parte integrante de um sistema, considerado como um recipiente de contenção destinado a cobrir, envasar, proteger, manter os produtos. É também uma ferramenta de divulgação, promoção e apresentação do produto (GURGEL, 2007; MESTRINER, 2002; NEGRÃO; CAMARGO, 2008; JEDLIČKA, 2009).

$O$ design de embalagens deve integrar todas as áreas de desenvolvimento, produção, uso e descarte para que possa cumprir eficientemente todas as suas funções. $O$ design é componente integrador do sistema de embalagem, por estar presente desde o início da concepção do produto, durante o qual o tipo e a forma da embalagem são definidos considerando todas as etapas.

Como instrumento comunicacional, e seu aspecto semiológico, o designer (emissor) identifica uma necessidade e elabora o projeto gráfico e estrutural contendo uma mensagem que deve ser apreendida pelo consumidor (receptor) (FERRARA, 1993; GURGEL, 2007; LAUTENSCHLÄGER, 2001; SANTAELLA, 2005).
Quando um indivíduo interage com a embalagem, o resultado desejado pode ser algum tipo de mudança em crença ou no comportamento. Uma abordagem dos fatores humanos pode tornar os projetos de design mais eficazes, ajudando a visualizar e melhorar a experiência do usuário e com o foco nos aspectos físicos e psicológicos ao usar os produtos.

Segundo Dougherty (2011), essa abordagem impulsiona as vendas, desenvolvem o valor da marca e ajudam a determinar o sucesso ou o fracasso de um produto. Aumentar o índice de resposta é uma das ações mais ecológicas que podem ser feitas pelos designers porque ele realmente atinge os resultados desejados.

As escolhas feitas na hora do consumo manifestam a forma como se vê o mundo. $O$ consumo envolve coesão social, produção e reprodução de valores; desta forma, não é uma atividade neutra, individual e despolitizada. Por isso é necessário conhecer o consumidor para o desenvolvimento das embalagens.

É função do designer: analisar, interpretar e propor signos que solucionem as necessidades físicas e visuais, otimizando recursos, para obter a embalagem adequada, esperando com isto estabelecer um processo de comunicação e satisfazer as necessidades tanto do fabricante como do consumidor (GIOVANNETTI, 2000).

\subsection{Percepção dos consumidores das especificidades dos orgânicos}

Para esta pesquisa, foram entrevistados 32 consumidores de alimentos industrializados, classificados por perfil de consumo de orgânicos (figura 2).

O objetivo foi verificar se havia diferença entre os consumidores regulares e os que têm pouco conhecimento ou não consomem produtos orgânicos, para que a pesquisa pudesse expressar a opinião dos consumidores em geral. A figura 2 mostra o perfil do consumidor por conhecimento do que é um alimento orgânico por frequência de consumo.

$\mathrm{Na}$ entrevista com os consumidores, foi pedido aos entrevistados que definissem o que é um alimento orgânico. Para avaliar estas definições, foi considerado correto quando as pessoas respondiam pelo menos um dos aspectos da produção orgânica. A grande maioria, 24 das 32 declarações, disse que o alimento orgânico é aquele produzido sem agrotóxico e em segundo lugar, em 19 vezes, ele foi definido como um alimento mais natural, e em terceiro, em 14 vezes como um produto com uma produção diferenciada. 
Apenas nove pessoas declararam que a produção do orgânico tem como preocupação a preservação do ambiente em que é produzido, sendo oito consumidores frequentes e apenas um consumidor do grupo com conhecimento, e não consumidor e um do grupo dos não consumidores e com pouco conhecimento.

Mesmo conhecendo um pouco o que é um alimento orgânico, alguns consumidores ainda não consomem com muita frequência. $O$ principal motivo de- tivo e três declararam que não consomem por falta de interesse.

Um dos questionamentos analisados na entrevista foi se o consumidor relaciona o alimento orgânico ao alimento mais saudável. Para isso, foi pedido para que ele separasse os produtos apresentados em saudáveis e menos saudáveis. As marcas que os consumidores demonstraram mais dúvida, seja por demorar mais ou por comentarem durante a separação, foi a Jasmine (cinco ve-

Figura 2 - Perfil do consumidor por conhecimento e frequência de consumo.

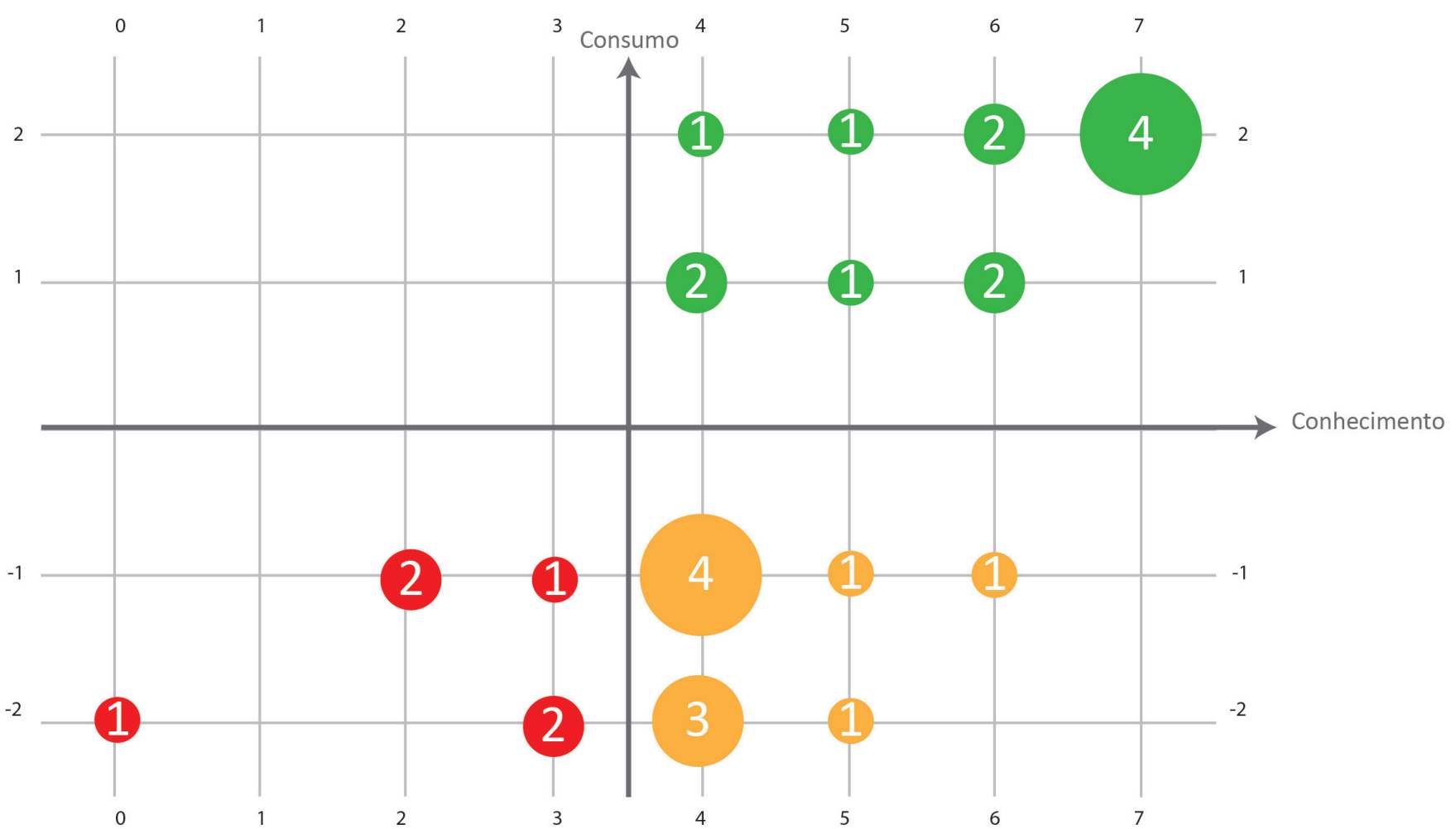

\begin{tabular}{|c|c|c|c|c|}
\hline \multicolumn{2}{|c|}{ Conhecimento do orgânico (um ponto para cada) } & \multicolumn{2}{|c|}{ Frequência } & Perfil de consumo \\
\hline Sabe definir & $\begin{array}{l}\text { Impacto menor no meio } \\
\text { ambiente }\end{array}$ & 2 & Sempre & Conhece e consome sempre \\
\hline Separa corretamente & $\begin{array}{l}\text { Sabe a diferença de } \\
\text { selos de certificação }\end{array}$ & 1 & Regularmente & $\begin{array}{l}\text { Conhece e não consome } \\
\text { (ou consome raramente) }\end{array}$ \\
\hline $\begin{array}{l}\text { Identifica ou conhece o } \\
\text { selo SisOrg }\end{array}$ & Conhece uma marca & -1 & Raramente & $\begin{array}{l}\text { Não conhece e não conso- } \\
\text { me }\end{array}$ \\
\hline $\begin{array}{c}\text { Identifica ou conhece a } \\
\text { certificadora }\end{array}$ & & -2 & Nunca & $\begin{array}{l}\text { O tamanho e o número dentro das } \\
\text { circunferências correspondem à } \\
\text { quantidade de consumidores }\end{array}$ \\
\hline
\end{tabular}

Fonte: Autores

clarado é a percepção de que o alimento orgânico é um alimento mais caro, para poucos: oito dos 29 entrevistados mencionaram o preço do orgânico como algo nega- zes), a Gran Pure (quatro vezes) e a Mãe Terra (três vezes).

A categoria palavra "orgânico" foi mencionada 42 vezes como critério para a separação, em 58 vezes que 
foi pedido esse procedimento. $O$ selo de certificação foi mencionado apenas quatro vezes.

A marca também foi a informação mais mencionada como critério para a separação como saudável ou não saudável, aparecendo 19 vezes. A presença de uma marca conhecida fez com que algumas pessoas separassem sem nem mesmo olhar a sua composição, pois confiam nela. A marca mais associada aos orgânicos foi a da Mãe Terra, citada por 15 consumidores. Em segundo lugar, aparecem empatadas a Jasmine e a Taeq, com três citações, e em terceiro lugar a Via Pax Bio, com duas citações.
Os principais critérios para a separação como mais saudável foram: a palavra "orgânico" (cinco consumidores), a aparência do produto (quatro consumidores) e a marca Mãe Terra (três consumidores). A composição nutricional, destacada no gráfico abaixo, foi citada por apenas um consumidor. Os principais critérios para a separação como menos saudável foram: por não ter a palavra "orgânico" (quatro consumidores), a aparência do açúcar (três consumidores) e a marca desconhecida (dois consumidores).

As marcas de açúcar mascavo separadas como orgânicas foram a Planeta Verde, Vitalin, Jasmine, Via

Figura 3 - Embalagens apresentadas de açúcar mascavo orgânico e não orgânico

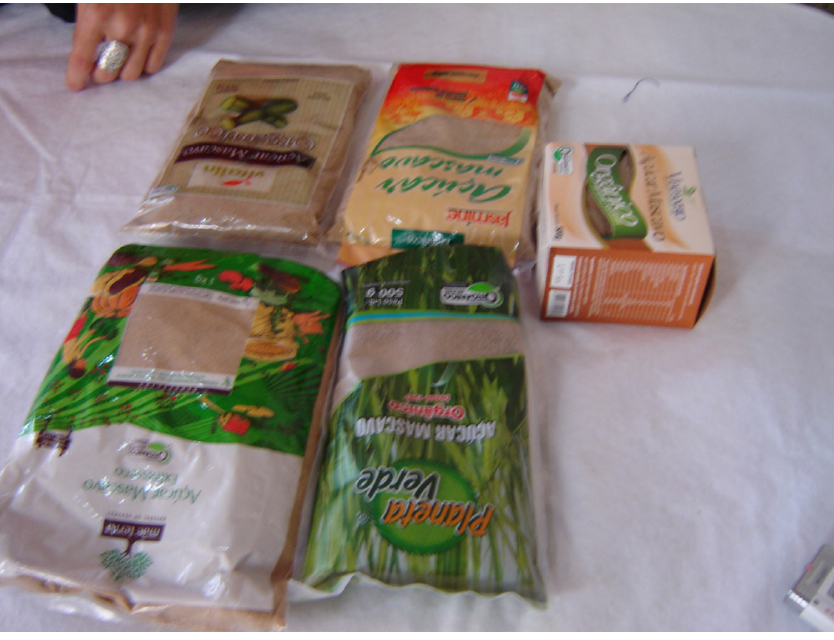

Quando os consumidores conheciam um pouco sobre a marca, mas não consumiam orgânicos com frequência, em dois casos acabaram separando os produtos pela marca, mesmo não sendo.

\subsection{Experimento com os consumidores}

Para verificar se as embalagens de alimentos orgânicos comunicam a política de desenvolvimento de produtos declarada pelas indústrias, e se os consumidores percebem isso pela embalagem, 7 dos 32 consumidores entrevistados foram postos a manipular embalagens de diferentes marcas de açúcar mascavo orgânico e não orgânico.

As embalagens de açúcares orgânicos apresentados foram das marcas: Mãe Terra, Jasmine, Planeta Verde, Vitalin e Via Pax Bio. As marcas não orgânicas foram: Athenas, Viver Carrefour, Mais Vitta e Doces Puxa Puxa.

As marcas mais separadas como saudáveis foram a Mãe Terra e a Jasmine, por sete consumidores.

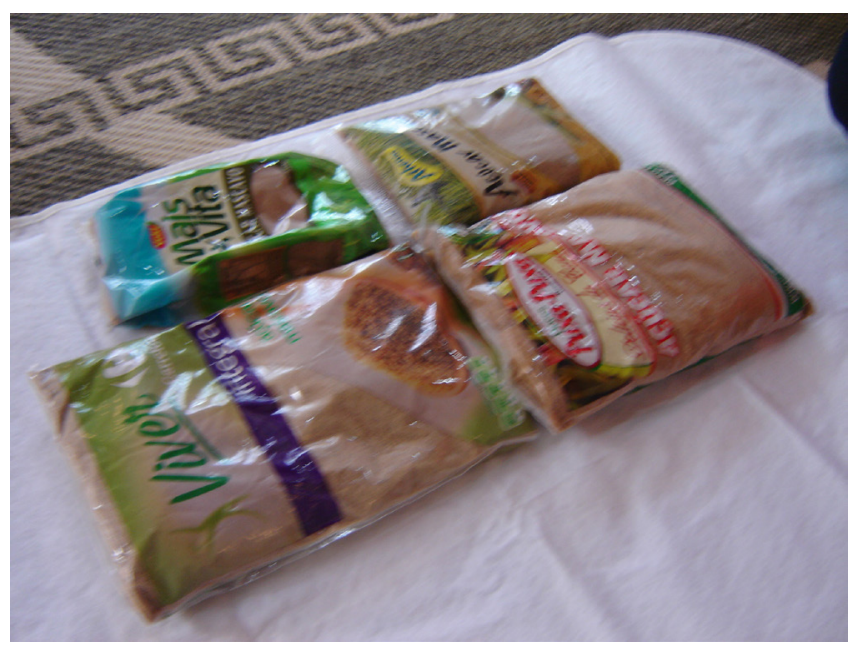

Fonte: Elisa Quartim.

Pax Bio e Mãe Terra, por todos os consumidores. Para separar em orgânico e não orgânico, a principal informação textual olhada foi a palavra "orgânico" (seis consumidores). O selo SisOrg apareceu em segundo lugar, para quatro consumidores, como critério de separação. Para separar em orgânico e não orgânico, a principal informação textual procurada, e não encontrada, foi a palavra "orgânico", por três consumidores. Para identificar como alimento orgânico, a informação textual e o selo SisOrg foram suficientes, havendo pouca dúvida.

Com base nos dados apresentados, podemos considerar que a aparência do produto é muito importante para o consumidor. Há, portanto, uma maior necessidade de que a embalagem tenha mais áreas transparentes e que possibilitem o consumidor a visualizar o produto sem ter de abrir a embalagem. 


\subsection{Análise das embalagens de açúcar mascavo orgânico}

$\mathrm{Na}$ análise da embalagem de açúcar mascavo da Via Pax Bio (figura 4) segundo o sentido de leitura, de cima para baixo, da esquerda para a direita, a primeira informação do painel frontal é a marca Via Pax Bio, porém a primeira informação a ser lida é a faixa verde com a palavra "Orgânico", por sua forma diferenciada e cor em contraste com o fundo em degradê do rosa até o branco. pior visualização. Porém, o olho favorece a zona inferior esquerda de qualquer campo visual, segundo o padrão de varredura. A faixa verde localizada no centro geométrico da embalagem faz com que o olho reaja a esse impulso perceptivo. A localização do selo facilita a sua leitura por estar em uma área de grande tensão visual.

Os elementos gráficos estão em equilíbrio, onde a faixa forma uma linha horizontal marcante e a composição centralizada, simétrica e regular, forma uma linha vertical

Figura 4 - Embalagem de açúcar mascavo Via Pax Bio e análise da hierarquia de leitura.

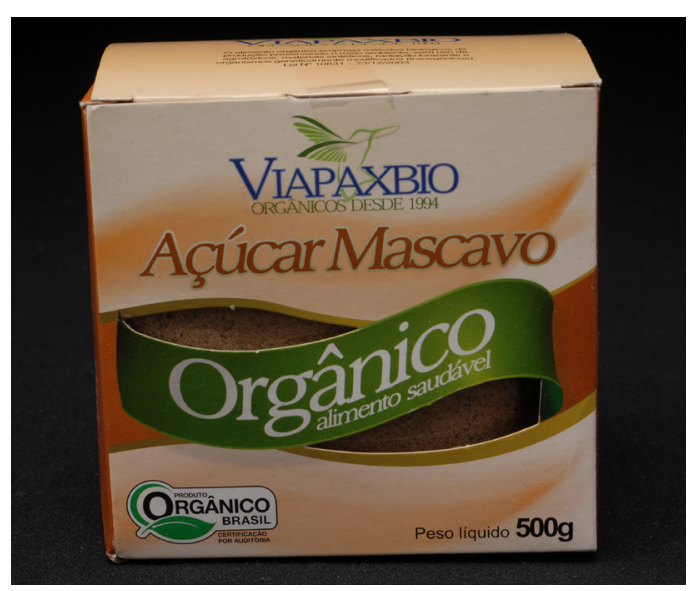

A marca da Via Pax Bio é aplicada sobre um fundo claro, dando boa leitura em contraste com as cores da marca, que são o azul e o verde escuro.

A janela no centro do painel frontal permite visualizar apenas uma pequena parte do produto dentro da embalagem. A escolha do marrom está relacionada à cor do produto em um tom mais escuro destacando o produto.

A faixa verde divide ao meio a janela e tem a informação "Orgânico, alimento saudável". Essa faixa verde, por sua forma e cor, é o principal destaque desse painel, sendo mais visível que o nome do produto, mostrando visualmente, principalmente, a importância de ser um alimento orgânico e dando a identidade da linha de produtos, pois se repete em produtos de outras linhas da Via Pax Bio.

A classificação do produto fica logo ao lado da palavra açúcar e é feita pela palavra "mascavo". A cor do texto é a mesma cor das laterais da embalagem. A tipografia escolhida também permite uma boa leitura, seja pelas cores em contraste com o fundo ou por seu tamanho.

O selo de certificação de orgânico, SisOrg, é aplicado no canto inferior esquerdo. Se considerarmos o sentido de leitura da embalagem, ele está localizado no canto de imaginária no centro, harmonizando a sua composição.

O açúcar mascavo Via Pax Bio segue o mesmo padrão de design dos outros produtos da linha de ingredientes.

Quanto à hierarquia de leitura (figura 4), o painel frontal é o que contém as principais informações do produto. Os painéis laterais, por sua localização, são lidos em uma segunda etapa, mas a cor chama mais a atenção. E é apenas na lateral que é apresentado um texto explicando a forma de produção diferenciada de um produto orgânico com o objetivo de redução de impacto ambiental. O texto tem quatro parágrafos sobre a empresa. O primeiro parágrafo é o primeiro a ser lido, por estar em negrito e pelo contraste com a cor do fundo.

O texto, que é o mesmo em todas as embalagens da linha, usa um tipo sem serifa, alinhado à esquerda, condensado, dificultando a leitura. O primeiro parágrafo em negrito enfatiza a informação de que se trata de uma das primeiras empresas orgânicas brasileiras. O segundo e terceiro parágrafo, na mesma fonte, mas sem negrito, conta um pouco mais sobre a empresa e sua história. O último parágrafo, também sem negrito, indica o site e forma de cadastro.

A cor do texto nos primeiros três parágrafos é branca, 
contrastando com o fundo marrom escuro, e o último é impresso em uma cor em um tom mais claro, parecido com o fundo, se diferenciando dos outros parágrafos.

Figura 5 - Base da embalagem de açúcar mascavo Via Pax Bio.

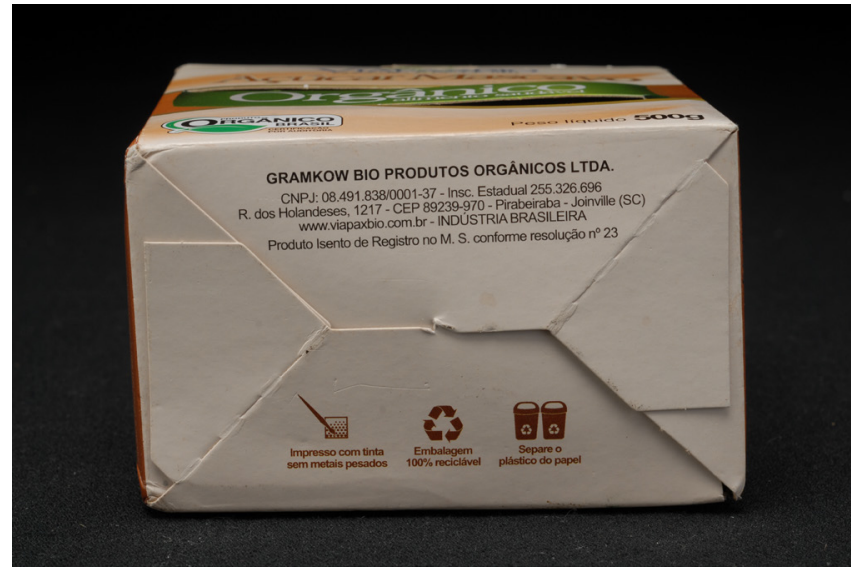

Fonte: Autores.

A base é o último painel a ser lido, por estar escondido. Na gôndola do supermercado, o produto é exposto na vertical. Nela contém as informações "Impresso com tintas sem metais pesados"; "Embalagem 100\% reciclável"; e "Separe o plástico do papel", importantes para o consumidor, porém escondidas. Foi percebido por apenas um consumidor.

A busca por fornecedores de embalagens que não utilizem materiais com substâncias perigosas, ou com cer- como embalagem secundária para a apresentação do produto e impressão das informações, e poderia não ser utilizada colocando as mesmas informações na embalagem primária plástica.

A Via Pax Bio tem ações de minimização do uso de recursos naturais, como a filtragem da água utilizada e a própria construção da fábrica, porém não fez o rastreamento dos impactos ambientais formalmente, e também não comunica a respeito na embalagem.

$\mathrm{Na}$ análise do conteúdo das entrevistas com os consumidores observa-se que a embalagem da linha de ingredientes da Via Pax Bio foi percebida como positiva por ser orgânica e por estar em uma embalagem fechada a vácuo. Porém, mesmo gostando da embalagem, percebe-se que o consumidor considera a segunda embalagem um desperdício de material e ainda atrapalha a visibilidade do produto, considerada importante para essa categoria.

$\mathrm{Na}$ análise da embalagem do açúcar mascavo da Mãe Terra (figura 6), segundo o sentido de leitura, de cima para baixo, da esquerda para a direita, a primeira informação do painel frontal é a marca Mãe Terra.

A hierarquia de leitura da embalagem de açúcar mascavo da Mãe Terra demostrada abaixo (figura 6) faz com que informações mais relacionadas à marca tenham mais destaque do que as informações mais específicas do produto.

A ilustração é a primeira informação visual a ser vista, pelas cores em contraste com o fundo branco. A marca é aplicada sobre o fundo banco, dando boa visibi-

Figura 6 - Embalagem do açúcar mascavo Mãe Terra e análise da hierarquia de leitura.
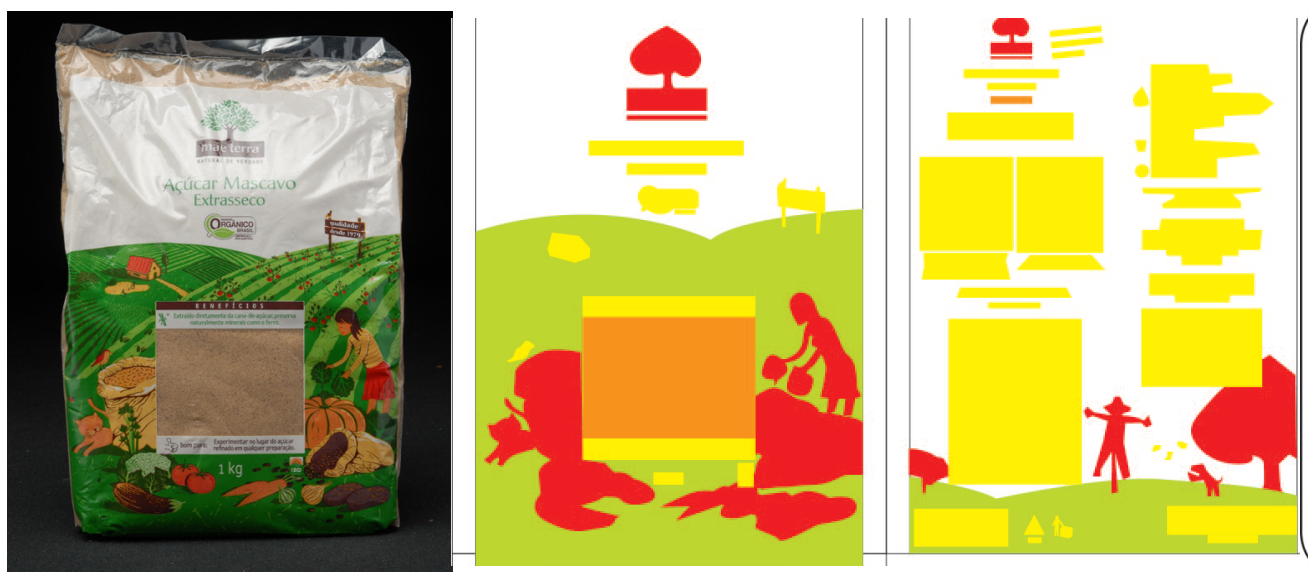

Hierarquia de leitura

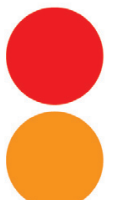

$1^{\circ}$ Lugar
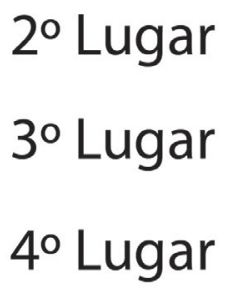

Fonte: Elaborado pelo autor, com base na pesquisa realizada.

tificação ambiental, é uma atitude que poderia ser considerada por todas as empresas.

O papel, material de fonte renovável, é utilizado lidade e contraste de cor. O nome do produto em verde, com tipografia de serifas simples, contrasta com a cor do fundo, sendo bem legível. 
A hierarquia de leitura da embalagem da farinha de trigo integral da Mãe Terra faz com que informações mais relacionadas à marca tenham mais destaque do que as informações mais específicas do produto.

O selo SisOrg abaixo do nome do produto tem o mesmo peso visualmente, não se destacando, e por ter outra informação abaixo com o mesmo peso e cor. Foi observado nas entrevistas, que, nessa localização nas embalagens, apesar de estar no centro ótico ou geométrico da embalagem, localização que teoricamente daria boa visibilidade, algumas vezes a indicação não foi vista em um primeiro momento.

As informações que explicam os diferenciais de produção pensando na redução de impacto ambiental, e a simbologia técnica de identificação dos materiais, es- os princípios considerados no rastreamento de impacto ambiental feito em um período anterior à entrevista. inclui os princípios ambientais e de saúde da Mãe Terra.

O box do projeto Pensando Bem, que apresenta de forma sintética o trabalho de rastreamento dos produtos Mãe Terra, porém sem ficar claro de que as informações eram específicas do açúcar mascavo ou de todos os produtos da linha.

A linha de ingredientes da Mãe Terra tem uma estrutura visual marcante que reforça a imagem da marca de produtos naturais e saudáveis. A unidade visual se dá principalmente pela ilustração e pelas cores com destaque para o verde e o fundo branco das embalagens. Nas entrevistas com os consumidores, ela foi facilmente reconhecida.

Figura 7 - Simbologia técnica de identificação de materiais, Box Pensando Bem que mostra as informações rastreadas e box Como desenvolvemos nossos produtos?
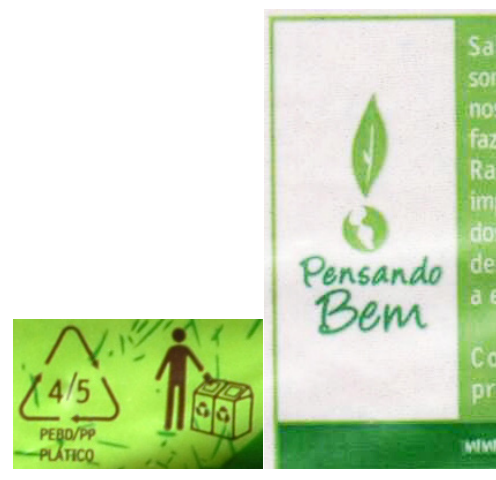

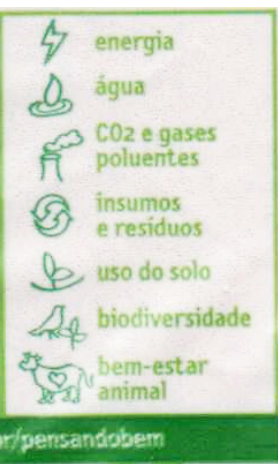

\section{COMO DESENVOLVEMOS NOSSOS PRODUTOS?}

Nós, da Mãe Terra, acreditamos no impacto positivo que um alimento direto da natureza traz à vida das pessoas. Por isso, criamos um guia para o desenvolvimento dos produtos Mäe Terra:

NATURAL DE VERDADE, carta de princípios dos nossos produtos:

Mais integrais, menos refinados: mai

vitalidade, mais próximos da natureza, mais nutrientes e fibras:

Sem conservantes e aromatizantes artificiais: quando necessários, usamos apenas os naturais;

- Sem açúcar branco: só utilizamos mascavo e demerara;

Q Niveis moderados de sódio: para uma dieta mais saudável;

Sem trans:não utilizamos gorduras trans em nossos produtos;

Livre de transgênicos:nenhum produto utiliza ingredientes transgênicos; Orgânicos:sempre que possivel, A. optamos por ingredientes orgânicos.

Para saber mais, acesse: Www.maeterra.com.br/naturaldeverdade

Fonte: Elaborado pelo autor, com base na pesquisa realizada. tão localizadas na parte de trás da embalagem, e por isso, com menos destaque. São utilizados ícones que orientam o consumidor a não jogar a embalagem na rua e sim em uma lixeira.

O box Como desenvolvemos nossos produtos? apresenta a carta de princípios da Mãe Terra, que mostra

\section{CONCLUSÃO}

As considerações finais deste artigo sobre as embalagens de açúcar mascavo orgânico se basearam na legislação brasileira para a certificação de orgânicos. Foi avaliada qual foi a política estabelecida para divulgação dos 
diferenciais dos orgânicos no design das embalagens de seus produtos, se essa política se reflete nas embalagens e se são percebidas pelos consumidores.

Baseado no que foi declarado pelas empresas, foi observado que as indústrias pesquisadas priorizam os aspectos mercadológicos das embalagens, deixando os aspectos ambientais em segundo plano, mostrando um distanciamento em relação ao discurso e à ação no que compete ao desenvolvimento de embalagens.

No que diz respeito à percepção dos consumidores para diferenciar o produto como orgânico e não orgânicos podemos observar que a maioria dos consumidores os identificou principalmente pela palavra "orgânico" na embalagem.

Nos casos em que o consumidor conhecia melhor o que é um alimento orgânico, além de perceber logo a palavra, buscou outras informações relacionadas à produção dos produtos, mostrando que o consumidor mais frequente de orgânicos valoriza outros aspectos do produto além dos nutricionais e da identificação com a marca.

Apenas a embalagem da Via Pax Bio usa como estratégia de divulgação o fato do alimento ser orgânico, sendo essa a informação com mais destaque em suas embalagens. Nas embalagens de produtos orgânicos da linha de ingredientes da Mãe Terra, se limita em colocar os selos de certificação, obrigados pela legislação, no tamanho mínimo permitido e em uma área com pouco destaque, mostrando que priorizam outras informações nas embalagens.

Todas as indústrias, para venderem orgânicos, são obrigadas a utilizar o selo SisOrg, porém o local onde ele é aplicado na embalagem pode facilitar ou dificultar a sua identificação pela hierarquia de leitura. Na análise das embalagens, foi observado que, quando há muitas informações no painel frontal, o selo perde destaque e visibilidade.

O consumidor, mesmo não o conhecendo, o identificou para separar a embalagem como orgânico, mostrando que o desenho gráfico criado é eficiente na sua função de comunicar e identificar. Sua identificação só foi dificultada nos casos em que estavam localizado em áreas menos visíveis pela hierarquia de leitura.

Considerando o que foi exposto, conclui-se que a forma de comunicar as especificidades dos alimentos orgânicos podem ser mais exploradas nas embalagens e cabe ao profissional de design orientar a empresa de forma adequada, mesmo quando isso não é estabelecido no briefing inicial.

O designer deve investir na parceria com as indústrias e se posicionar como consultor no que diz respeito ao design de embalagens com menor impacto ambiental, mesmo quando o produto não tem essa característica, sendo um integrador das diversas áreas de desenvolvimento de embalagens.

\section{REFERÊNCIAS}

1. BAUER, M. W.; GASKELL, G. Pesquisa qualitativa com texto, imagem e som: um manual prático. Petrópolis: Vozes, 2002.

2. BRAUNGART, M.; MCDONOUGH, W. Cradle to cradle: re-making the way we make things. London: Vintage Books, 2008.

3. DONDIS, D. A. Sintaxe da linguagem visual. 2. ed. São Paulo: Martins Fontes, 1997.

4. DOUGHERTY, B. Design gráfico sustentável. São Paulo: Edições Rosari, 2011.

5. EMBRAPA. Princípios norteadores da produção orgânica de hortaliças. Brasília: 2008.

6. FERRARA, L. d'A. Leitura sem palavras. 3. ed. São Paulo: Ática, 1993.

7. FLICK, U. Introdução à pesquisa qualitativa. 3. ed. Porto Alegre: Artmed, 2009.

8. GIOVANNETTI, M. D. V. El mundo del envase: manual para el deseño y producción de envase y embalajes. 3. ed. Barcelona: Gustavo Gili, 2000.

9. GURGEL, F. A. Administração da embalagem. São Paulo: Thomson Learning, 2007.

10. HOFFMAN; D. Inteligência visual: como criamos o que vemos. São Paulo: Campus, 2001.

11. JEDLIČKA, W. Packaging sustainability: tools, systems and strategies for innovative package design. Hoboken: John Wiley and Sons, 2009.

12. KAZAZIAN, T. (org). Haverá a idade das coisas leves: design e desenvolvimento sustentável. 2. ed. São Paulo: SENAC, 2005.

13. LAUTENSCHLÄGER, B. I. Avaliação de embalagem de 
consumo com base nos requisitos ergonômicos informacionais. 2001. 109 f. Dissertação (Mestrado em Engenharia de Produção). Universidade Federal de Santa Catarina, Florianópolis, 2001.

14. MAPA - MINISTÉRIO DA AGRICULTURA, PECUÁRIA E ABASTECIMENTO. Instrução Normativa n' 50/2009, de 29 de maio de 2009. Institui o selo único oficial do Sistema Brasileiro de Avaliação da Conformidade Orgânica. Disponível em: <http://extranet.agricultura.gov.br/sislegis/ action/detalhaAto.do?method=recuperarTextoAtoTematicaPortal\&codigoTematica $=1501059>$. Acesso em: 15 jun. 2011.

15. MANZINI, E., VEZZOLI, C. O desenvolvimento de produtos sustentáveis: os requisitos ambientais dos produtos industriais. São Paulo: EDUSP, 2002.

16. MESTRINER, F. Gestão estratégica de embalagem: uma ferramenta de competitividade para sua empresa. São Paulo: Pearson Prentice Hall, 2007.

17. NEGRÃO, C.; CAMARGO, E. Design de embalagem: do marketing à produção. São Paulo: Novatec Editora, 2008.

18. ROSA, M. V. de F. P. do C.; ARNOLDI, M. A. G. C. A entrevista na pesquisa qualitativa: mecanismos para validação dos resultados. Belo Horizonte: Autêntica, 2006.

19. SANTAELLA, L. Semiótica aplicada. São Paulo: Pioneira Thomson Learning, 2005.

20. TRIVIÑOS, A. N. S. Introdução à pesquisa em ciências sociais: a pesquisa qualitativa em educação. São Paulo: Atlas, 1987 